\title{
The Everyday Paths to Equalize Oneself: Emphasizing Vs. Rejecting Group Membership among Working Class Ethiopian-Israelis
}

\author{
Adane Zawdu \\ Department of Sociology, University of Connecticut, United States
}

Copyright $(2016$ by authors, all rights reserved. Authors agree that this article remains permanently open access under the terms of the Creative Commons Attribution License 4.0 International License

\begin{abstract}
Following recent studies on everyday de-stigmatization processes [1], I examine in this paper the culture resources working class Ethiopian-Israelis mobilize to contest stigmatized notions of Ethiopianness. Based on 30 in-depth interviews, and an ethnographically informed analysis of those interviews, I present two types of culture resources. The first is the use of "Ethnic Culture," in which Ethiopianness is presented as unproblematic ethnic distinctiveness, and non-Ethiopian Israelis are grouped along ethnic lines of different, but equally valued groupings. This is a strategy that emphasizes group membership and handles ethnic distinctions as commonsensical. The second is the use of "Universalism," in which all potential group memberships are rejected as meaningless for individual self-identification and evaluation. This strategy emphasizes equality on universal ground and uses various all-inclusive criteria. Guided by two distinct logics, emphasizing vs. rejecting group membership, both strategies are oriented towards creating horizontal relations with others. While previous studies emphasized the role of racial and national boundaries in the de-stigmatization processes among Ethiopian Israelis, the variations in this paper shed light on the working of ethnicity as a commonsensical source of value; thus, enabling us to further specify the different logics behind the absence of racial language among ordinary Ethiopians, and the varied degrees to which national boundaries matter in everyday contestation over stigmatized notions of group membership.
\end{abstract}

Keywords De-stigmatization, Israelis of Ethiopian origin, Ethnic and Racial Boundaries, Nationhood

\section{Introduction}

In their book, Getting Respect: Dealing with Stigma and Discrimination in the United States, Brazil and Israel, Lamont et al. [1] explore everyday de-stigmatization processes. The study's cross national comparative depth and scope enrich our understanding of variations in micro-coping management. It also illuminates these variations' relations to particular national configurations of available cultural repertoires, institutional history, and positioning within the symbolic order of belonging and membership. In this paper, I respond to the call made by Lamont et al. [1:286-288], to further develop our understanding of the variations within cases and the mediating relations they take with the broader social context.

I look at one segment of a particular group, working class Israelis of Ethiopian origin, and explore which kind of cultural resources they deployed in the process of transforming stigmatized notions of Ethiopianness and gaining self-worth. Based on 30 in-depth interviews, and the ethnographically informed analysis of these interviews, I present two types of resources: Ethnic Culture and Universalism. In so doing, the study not only brings additional variations of the cultural resources deployed in the process of de-stigmatization among Ethiopian-Israelis [2-3], but also sheds light on: 1. How, amidst racial distinctions, ethnicity works as a commonsensical frame to account for social difference and to transform stigmatized notions of group membership. 2. The varied ways in which national frameworks of peoplehood mediate de-stigmatization processes at the level of everyday life.

This paper is in conversation with previous studies that explored everyday de-stigmatization processes among Ethiopian Israelis [1-6-2-3]. These studies emphasized strategies that organize along the following principles: 1 . Emphasizing difference within the national context of Israeli Jews, through emphasizing sameness with transnational notions of blackness as a source of value and a model to contest local stigma. 2. Downplaying difference within the national context of Israeli Jews, through emphasizing sameness with national notions of Jewishness as a source of value and claim making for equality. In 
contrast, the variations presented in this paper exist between (ethnic) and outside (universalism) of those two poles.

"Ethnic Culture" refers to a strategy where interviewees located the source of stigma primarily in the de-value of "Ethiopian culture" and its carriers as backward, but nonetheless accounted for equality on the basis of group membership as Ethiopians. Leaving no one unmark ethnically, ethnicity was seen as a basic and unproblematic feature for all individuals. As such, Ethiopianness was constructed as an ethnic distinctiveness that exists in a categorical set of horizontal relations with equally valued and meaningful ethnic groupings [4]. "Universalism" refers to a strategy where interviewees located the source of stigma in several sources: blackness, ethnic culture, class, and more, but nonetheless dismissed them as meaningless and accounted for equality on universal ground of shared characteristics [5]. Both lines of action sustain one's dignity as an individual and establish horizontal relations with others.

The use of "Universalism" informs us of strategies that do not organize in relation to national and transnational categories. This variation invites us to contextualize when and how global and national notions of peoplehood participate in shaping peoples' strategies and how, amidst powerful national narratives of belonging, as in the Ethiopian Israeli case, people turn to non-national resources. The use of "Ethnic Culture" exists between these poles of emphasizing racial difference vs. ethno-national sameness, although not as a 'middle-ground.' It's a line of action that makes reference to racial distinctions, but emphasizes ethnic differences as commonsensical and meaningful. The commonsensical way in which people use Ethnic Culture to transform stigmatized relations teaches us that Ethiopianness, as a taken for granted form of ethnic distinctiveness, is sustained by the salient of ethnic classification in everyday life and institutional work in Israel [7-8-9 $]^{1}$, the thickness of Ethiopianness as a cultural experience, and the absence of racial categories in institutional contexts [10].

The use of Ethnic Culture also informs us that Ethiopianness, as a form of racial distinctiveness, not only gets negotiated and contested in relation to the boundaries of national belonging (i.e., exclusion as blacks), as shown by different studies [11-12], but also in relation to non-national commonsensical patterns of everyday lived experience. Thus, we are enabled to further specify the different logics behind the absence of racial language among ordinary Ethiopians. However, interviewees' use of Ethnic Culture within a categorical set of horizontal relations, and not vertical or politicized relations [5], might point to a mediating role of the national context, shaping the rules of engagement between citizenry, and more so than just the particular content of such engagement.

${ }^{1}$ The degree to which ethnicity is salient varies by class and geography [13].
In the following sections, I will first present the background of the group at the heart of the study, starting with the particular way in which Ethiopian Jews got incorporated within the symbolic boundaries of Israeli nationhood, and emphasizing the role of migration narratives and notions of resemblance and difference. Next, I describe how Ethiopianness is a potential stigmatize marker, with varied sources that feed into it. Accounting for the different potential sources helps us understand that the variations in coping management shown in different studies also corresponds to the different forms stigmatized Ethiopianness takes. In the following section, I discuss previous studies on stigma management among Ethiopians and the added value of this study. After presenting the methodology, I elaborate on the analysis of two variations in coping and transforming stigmatized notions of Ethiopianness. Finally, I discuss how these variations shed light on our understanding of how everyday experiences shapes coping strategies with stigmatized notions of group membership.

\section{Background}

\subsection{Group Migration and National Membership}

The individuals at the center of this study, working class Ethiopian Israelis, are part of a larger and diverse community of Ethiopian Jews who migrated to Israel since the late 1970s [14-15]. As the newly established Nation-State institutionalized Jewishness as the criteria for migration and access to full political rights [15], Ethiopian Jews' membership was put into question. Recognition along normative Judaism and hence, access to citizenship, was contested and characterized by political struggle that was resolved in the mid-70s [16-14]. At the heart of this process was the question of the degree to which the group resembled the national community, imagined along primordial ethno-religious notions of peoplehood [16].

Ethiopian Jews' visible darker skin, non-rabbinical practice of Judaism, and non-modern form of life made them subject to varying forms of scrutinizing over the legitimacy of their membership [14-16]. Nonetheless, Ethiopian Jews' collective identification, and the particular way the Nation-State recognized their right for national membership, where both constructed through a non-racial framework of primordial kinship commonalty among Jews. Notwithstanding contestation [17], this particular logic of symbolic incorporating, and the broader historical and political narrative that legitimizes and naturalizes it, got institutionalized in varying fields. High schools' textbooks and annual State-organized ceremonies are just a few examples [18].

Although individuals migrated from Ethiopia to Israel since the establishment of the State [14-15], the late 1970s mark the beginning of a collective State supported migration [15]. The migration of significant numbers took place in 
1977, with over one hundred arriving [14]. 1980-84 marks a major political transformation with a few thousand coming predominantly from the Tigray and Walkait regions, paving the route for others; once in Israel, organized politically to increase State intervention [16]. 1984-5 was the peak of State intervention, with major governmental operation "Operation Moses" taking place, which brought about 7,000 people, predominantly from the Amharic speaking regions. Post "Operation Moses" migration continued in smaller numbers until 1991, in which another governmental intervention, "Operation Solomon," took place, with about 19 thousand newcomers. Since the mid-90s, immigration from Ethiopia continues and consists of the so-called "Falashmura"- descendants of converted Jews [19-20]. As can be seen, in the pre-migration context, the group was differentiated along various lines, a process that intensified after their migration to Israel [21]. This is an important matter to notice, as many popular and scholarly representations of Ethiopian Jews as newcomer immigrants mask these important variations and transformations. Today, the group constitutes about 140 thousand people, making slightly less than $2 \%$ of the general population, and of which about a third are native born [22]. The population in this paper is made up of individuals who immigrated to Israel from the late 70 s to early 90 s.

\subsection{Ethiopianness as a Stigmatize Marker: Several Sources}

Ethiopianness as a stigmatized marker has different sources. Besides blackness, I will point to the following: State bureaucratic categorization, lower class position, and national narrative. Ethiopian Jews' migration to Israel was celebrated by the State as the trumpet of Jewishness over color differences and an expression of Jewish diversity. Nonetheless, studies have shown how this group was also the subject of stigmatization by state bureaucracy, which in turn contributed to a spoiled public image of Ethiopianness. Such works [23] reveal how, in early years, Ethiopian immigrants got classified as a "social problem" to be managed through special policies in an institutional context (e.g., "absorption centers," institutions that facilitate immigrants' integration process). This labeling continued irrespectively of duration in the country, which reinforced their position as a problematic category in an institutional context and in the public image [24].

In addition to state bureaucracy, their lower class position is also a source for a stigmatized association of poverty with Ethiopianness. Notwithstanding a vibrant civil society [25] and a growing professional middle class [26], analysis of social and economic status of Israelis of Ethiopian origin indicates that this group is located among the lowest levels in terms of education, housing, and employment [27]. Visible political protests against racism also added another layer of stigmatized associations with Ethiopianness. The
1996 "Blood Affair" violence, while adding to existing stereotypes, such as the lack of political power, also introduced a new stereotype of potentially "violent" people [11].

Analysis of public representations in national media coverage reveals how Ethiopianness gets constructed both along "negative" lines, such as "culturally ignorant," and along "positive" lines, like contributing to the "national strength" of Israel [28-29]. Exploring the relations between public representations and perceptions among non-Ethiopians shows that overall two types of perceptions get clustered into dominate images: an assembly of 'positive' stereotypes such as "good hearted," "noble," etc.; and another, of 'negative' stereotypes, such as "backward" and "uneducated," etc. [30].

While those public images might vary by the particular context of geography and news coverage, looking at the State's institutionalized formal national narrative on Ethiopian Jews' inclusion and migration, reveals how these contradictory meanings are held simultaneously. This formal narrative portrays Ethiopian Jews as family members returning home, at the cost of great suffering in the process, and as people who demonstrate historical resilience in the face of religious prosecutions. As such, the formal national narrative is a powerful equalizing mechanism, a source for self-worth and claim for equality, and as well as a frame with which to construct social resemblance amidst other competing principles, chief among them, race.

However, as pointed out by the scholar Hananya Vanda [16-21], this narrative is also organized as a story of a heroic rescue mission, in which the State is the main protagonist and Ethiopian Jews are the homogeneous passive object for rescue. Coined by Vanda [21] as the "Zionist Ethos of Rescue" [21], this particular way of organizing the narrative de-politicizes the struggles for inclusion, masks activists and ordinary people's agency in that process, and homogenizes the migration processes and historical experiences of diverse people. This critical reading of the formal narrative got crystallized and widely circulated starting in the mid-2000s [32]. As with other Jewish groups [33], narrating the migration process by the State as a type of a "rescue mission" reaffirms one of the Nation-State's core justifications - a safe haven for Jews.

To conclude, while Ethiopianness carries positive weight in the Israeli context, it is also a potential stigmatized marker that can take different meanings, and its particular activation is context-sensitive. Thus, everyday acts of stigmatization take place in a context of potential ambiguity and contestation over the source that feeds into the stigmatization. Furthermore, its potential to stigmatize exists in a national context of varied social divisions and stratification systems - of which, Ethiopianness is one out of several stigmatized categories of people [10]. For example, color

\footnotetext{
${ }^{2}$ The case: it was revealed that Ethiopians' blood donations were selected and thrown away, which was followed by demonstrations that turned violent [31]
} 
based stigma might cut across groups [34], and the most salient division and source of stigma is the Palestinian/Israeli Jews division, in which Ethiopians are part of the Israeli Jews majority. Such stratification systems complicate the context in which Ethiopian Israelis experience and cope with stigmatization.

\subsection{Previous Studies on Ethiopian-Israelis' Stigma Management}

Different studies have attempted to understand the ways in which Ethiopian-Israelis cope with the varied ways Ethiopianness is stigmatized in the Israeli context. Early studies, limited to the experience of new immigrants, argued that ethnocentrism has a greater influence than racism, as color based discrimination does not violate their sense of belonging to the national collective [35]. In contrast, others argue that skin color is the central axis around which Ethiopians' everyday stigmatizing experiences are organized [e.g., 36]. These studies, and others [e.g., 37], point to Ethiopians' awareness of varied forms of discrimination and that Ethiopians themselves experience Ethiopianness as a potential stigmatized marker with various sources (e.g., newcomers, ethnocentrism, class, color, state bureaucracy, etc.).

Another group of studies examined variations in coping management. Shabtay [38], for example, argues for generational differences, in which the first generation's firm attachment to Jewish identity enables a non-stigmatized source of value; while the second generation relied more on cultural and political forms of Blackness [39-40], which Shabtay and others [11] argue contributes to their racialization in the public eye, and thus deepens their marking as a distinct stigmatized black group.

This paper builds on these various studies. However, it also differs, as it moves away from focusing on new immigrants in a moment of transition or institutional context [36-35], or focusing on discourse agents and political class (i.e., activists, academics, artists, etc.) [40-11].

\subsection{Conceptual Framework and Scholarly Conversation}

Conceptually, this paper is anchored in the work of Erving Goffman [41] on micro processes of stigma management [42] and Michele Lamont's contemporary elaborations on de-stigmatization processes and variations [43-1]. "De-stigmatization Strategies" is a key term in this study. This concept was coined by Lamont [43] and refers to the ways in which individuals actively engage in changing the negative meanings attached to their identities, thus challenging the stereotypes that feed and justify the discriminatory treatment they face. This is a concept that orients us to pay attention to variations in coping management; types and levels of contexts.

Comparative works on de-stigmatization strategies in the Israeli context advanced our understanding of the ways in which the strategies deployed are linked to an individual's particular group position and the mediating role the broader national context has on constraining or enabling particular strategies. Mizrachi and Herzog's [2] comparison of ordinary Ethiopian Israelis, Palestinian citizens of Israel, and Mizrachi ${ }^{3}$ Jews teaches us that while all aim for participation in Israeli polity, the language of difference is avoided by both Mizrachim and Ethiopians, but not by Palestinians. While Palestinians use the language of racism, Mizrachim distance themselves from negative group identities and Ethiopians from the use of the language of race and racism. Such works argue that Ethiopians' position within the symbolic boundaries of national belonging (i.e., as Jews) makes them more prone to downplay the language of difference, which sustains their sense of belonging and shapes their experience and response to stigma. For example, through the language of new-comers/old-comers, which recognizes stigma as a temporary position [3], or through the language of Jewishness, as a ground for claim-making for equality through resemblance [12]. In contrast to the emphasis of resemblance, class comparisons of de-stigmatization strategies among Ethiopians reveal variations among highly educated individuals, who mobilize the global language of race and racism to contest local stigma.

Advancing our understanding of de-stigmatization processes, these studies present two poles of strategies - on the one hand, emphasizing difference through transnational notions of blackness as a source of value and a contestation model, and on the other hand, downplaying difference through ethno-national notions of Jewishness as a source of value and membership. However, the variations presented in this paper inform us of strategies within the same ethno-class position that don't organize in relation to, or against, national or transnational notions of peoplehood, and thus push us to contextualize more the ways and degrees to which national and transnational notions of difference matters. In this paper, I particularly pay attention to the ways in which, amidst racial boundaries, ethnicity works as a commonsensical frame to make sense of social difference and as a resource to transform stigmatized notions of group membership. I conclude by re-thinking the absence of racial language among ordinary Ethiopians, not as strategic downplaying, but rather, as corresponding to an alternative and commonsensical principal of vision in the Israeli context, which resonates with their social organization and everyday lived experience.

\footnotetext{
3 Jews of Middle Eastern and North African origin.
} 


\section{Methodology}

This work is based on the analysis of 30 in-depth, semi-structured interviews (15 women and 15 men) with working class Ethiopian-Israelis aged 25-60, which took place from 2008 to 2009 . The interview questionnaire was constructed as part of an international comparative study on de-stigmatization processes [6], and recruiting interviewees was done by a method of snowball sampling. Additionally, the analysis of the interview data is informed by 14 months of ethnography on everyday communal associations among Ethiopian Israelis, which took place from 2014 to 2015 in a southern city in Israel. Interviewees' profiles were chosen to focus on working class "ordinary people" (in contrast to discourse agents and activists) and who are "old-comers" (i.e., those who have spent most of their lives in Israel).

The study population consists of individuals with no more than a secondary education, with most having a high school education, and who are engaged in a variety of blue collar occupations: security, low-tech industrial, cleaning, etc. A few are in other occupations, such as non-professional clerks. They live in various cities that make up the Israeli social and geographical periphery. Their religious affiliations are mostly traditional, ${ }^{4}$ some are secular, and a few are orthodox. All respondents, apart from two, immigrated to Israel between 1977 and 1991, most of them when they were young (0-9), and others when they were in their teenaged years. Regions in Ethiopia from which respondents or their parents came were divided between Gonder and its surroundings and Tigray and Walkait (northern and northwestern Ethiopia), which are the historical settlements of Beta Israel in Ethiopia [14-45].

Most interviews were held in the interviewee's house and lasted between 1.5 and 2 hours. At the beginning of each interview, the respondents chose their own pseudonym. The interviews were recorded and later closely read to extract out of them important and repeating themes relating to interviewees' everyday experiences of negative labeling and their management of such cases [46-47-48].

\section{Analysis of Findings}

The two strategies highlighted in this paper are differentiated by the particular logic that interviewees used to de-stigmatize themselves and account for equality. The first is the use of "Ethnic Culture." Here, ethnic grouping is celebrated and presented as a taken for granted building block of social differentiation. Taking a view from this point, as interviewees did, reveal a world in which all individuals are marked and assigned ethnicities that are different by content and equal by value. The second strategy is the use of "Universalism." Here, all forms of ethnic grouping were rejected as potential sources of

\footnotetext{
${ }^{4}$ On the religious category of "traditional" in the Israeli context, see: [44].
}

discriminatory dispositions and as masking basic and important commonalities shared by all individuals. Although most interviewees made use of Ethnic Culture more than Universalism, I present the latter to demonstrate the varied relations de-stigmatization processes and nationhood might have.

Despite being guided by two opposing culture logics - blurring versus strengthening of group boundaries, both strategies are oriented towards creating horizontal relations with others. As such, I refer to them as equalizer resources. In both strategies, everyday experiences were used as a reference point for justifying the particular line of de-stigmatizing action and as a means of validating the action deployed - that non-stigmatized relations can exist.

\section{1. "Show You Have Something": Ethiopian Culture as an Equalizer Resource}

"Ethiopian culture" as an equalizer resource refers to a folk construction of Ethiopianness as an ethnic form to present in inter-personal relations and interactions and use in the assigning of out-group members to equally valued ethnic groupings [49]. While some components of this folk construction of Ethiopianness make the commonsensical "culture stuff" and imagery that constitute ethnic boundary [50-51], others less. Interviewees attributed and labeled a range of values and practices as "Ethiopian culture," from particular food, dress, holidays, and language, to a distinctive "mindset" and work ethics.

\subsection{1. "Just as I'm Interested in Someone from Tripoli": Individualistic Mode of Intervention and Relational Validation}

Asking about the available ways Israelis of Ethiopian origin have to change stigmatization and discrimination, Dana, a 29-year-old textile factory worker, illustrates the use of "Ethiopian culture" as an individualistic mode of intervention:

If every individual in society will look at it, like, with a little different perspective. ... Like today, I hear people say, "Wow, I did not know your culture until I came across my friend's son"- a mother told me, her son is in the army - "and so I understood how your culture is very wonderful." So, if everyone changes a little, and try to learn a little about others' culture and understand ... Then we will be a very different society.

Later in the interview Dana discussed how, in everyday non-formal interactions at work, she uses her "culture" to educate her colleagues and change their perceptions about Ethiopians. Confronting a co-worker depicting Ethiopian culture as "calm," a common stereotype signaling passivity [30], Dana replies:

And I said to her: "Listen, our culture is calm, true; but in its calm way, it generates a lot of things around. 
Which then somehow make people more ... thoughtful before they say something." So I told her. ... They did not know about Ethiopian culture. They knew, in general, about Ethiopians who come as clients. But I explain to them a lot about the holidays, I explain to them what we have, and what we do not have, what foods we have. Just as I'm interested in someone from Tripoli [Israelis of Libyan origin] ... what they do, then the same thing. It is kind of a [reciprocal] cycle. ... and listen, I think we have a very beautiful culture. There are many things to preserve ... that we can show to the Israeli society.

Dana's comment that "Ethiopian culture" is a resource to be "preserve[d]" and "shown to the Israeli society," was likewise stated by most of those interviewees that used "Ethiopian culture" as a way to de-stigmatize Ethiopianness. According to the reactions Dana received in the above interaction, and others mentioned throughout the interview, her line of action generates real change in interpersonal relationships and points out the relational dimension in such interaction-how out-group members participate in validating her use of ethic culture.

The individualistic mode of intervention that underlines Dana's words is expressed more directly by Yaakov, a 26-year-old supermarket worker, when he was asked about fighting discrimination:

I think the way to go is through our traditions, our culture. For everyone ... you don't need to build up a (political) party. In one's life, one shouldn't be ashamed in his traditions, culture, style of speech, past. The person shouldn't try to hide it, but show it to the world, and show that he also has something.

Like Yaakov, interviewees acknowledged the stigmatized gaze, and their active engagement in fighting it, but nonetheless, they didn't translate it into a collective action or an open pathway to politicization. Interviewees' focus on affirming "Ethiopian culture" was made along a specific understanding of why they are stigmatized: the negative perceptions of "their culture." Such negative perceptions were sometimes talked about through the idioms of lack and absent - "show you also have something." When asked generally about fighting discrimination and stigma, interviewees replied assuming an individualistic line of action in which "their culture" is the key for such positive transformation.

As seen earlier in how non-Ethiopians react discursively to Dana's presentation of Ethiopian culture and reaffirm her approach, interviewees' use of Ethnic Culture is shaped in relational processes in which non-Ethiopians actively participate in sustaining and validating its use. Later in the interview, Dana exemplifies consequences that go beyond earlier symbolic gesture:

This textile factory [work place], never had Ethiopian workers.... After me they put another one .... I think I made them understand, like, what Ethiopian worker can do. Or in general, what Ethiopian are worth. Today my manager looks at Ethiopians ... [as people] who have work ethics, honorable ... and since then, it opened some doors for others ... and I am very happy ... I made a group of, again, a group of... let's call them, "whites," who did not know [about Ethiopians] ... they knew, but did not know in-depth, the Ethiopian culture. But once you come and you show them....

Dana's words point to the folk construction of "Ethiopian culture," as it assumes a wide range of practices and values, from work ethic to a meditative mode of being, as mentioned earlier. Like Yaakov, Dana is not blind to the stigmatized gaze on Ethiopianness, and its stratifying consequences, like discriminatory job hiring. Other interviewees echo this, as well. Nonetheless, Dana maintains an a-political and individualistic account of it, and she refers to non-Ethiopians as ignorant subjects that can be changed with "in-depth" familiarity of "Ethiopian culture." This point of view is being experience as validated in her daily experiences, like with the example of the job hiring, and reaffirms her use of this line of action.

\subsubsection{Ethnic vs. Racial Categories}

Dana's use of ethnic labels throughout the interview was constant and unproblematic. However, the use of racial labels was minor and uncertain, as was with other interviewees who used Ethnic Culture. Dana's earlier reference to her job management staff as "a group of ... let's call them, "whites,"” might be interpreted as a hesitation that tells us of an active distancing from racial language. However, such an ambiguous relation to racial language among working class Ethiopians is better understood when taking into account how salient ethnic classification is in Israel, both in everyday life [9] and within an institutional context [7], making it a normative frame to account for social difference. By interpreting uncertainty in using racial language as an active distancing, as previous studies did, we miss the taking for granted work alternate classificatory systems do, and the effect they might generate, such as ambiguity when putting to use racial categories.

Keeping this in mind, I also take into account the following: State work around cultural distinctiveness and color blindness [10]; the commonsensical use of ethnicity in everyday life among non-Ethiopians; how stratification in Israel is organized along multiple axes, color being one of them; and how political uses of racial language is ambiguous outside of political circles engaging in global conversation on inequality [7-8-10-12]. The hesitated use of racial categories is not unique for Dana, the other interviewees, or Ethiopian Israelis in general. It expresses the social fact that in Israel, racial classification might stand in tension with other classificatory systems.

An example can be seen in a recent account of a well-known Israeli criminologist of European origin. In an interview on patterns of profiling and police violence 
against Ethiopian-Israelis [52], a growing public conversation taking place in the last few years, he explains:

The problem is not over-policing, (but) ... lack of cultural awareness ... excuse me for the terminology of black-and-white, but when a white police officer ... I think that every police officer should learn in police academy a course on culture awareness, towards Ethiopians, Bedouins, and every group who isn't regular here ...

Uncovering the structuring forces of such reduction of police violence to "cultural awareness" is beyond the scope of this paper. Nonetheless, the apologetic use of racial categories - only to dismiss them in a favor of ethnic categories-gives us a another view into the broader context in which the hesitated use of racial categories by Dana and other interviewees, exist. However, interviewees' use of ethnic categories differs from the criminologist's in one important way. The account above is in line with the hegemonic distinction between the ethnically marked and the un-marked in Israel, which tends to organize along the lines of European and Non-European [13]. In contrast, interviewees who used Ethnic Culture marked everyone else, too, and had an elaborated system of ethnic labels to account for horizontal relations. For example, Gidi, a 27-year-old security guard, when asked about a common stereotypical claim [30] - that in order get fully excepted, Ethiopians need to assimilate and discard their culture-he replies:

To the contrary, exactly to the contrary ... they need to accept us as who we are. Today you see Moroccans and others; I don't think they change. You know, their culture and everything. Like their music ... I don't think we need to change in order to get accepted, to the contrary, we need to be who we are, and I'm sure it will only do good to the society.

Like Dana's Libyans, Gidi refers to Moroccans when making comparisons and goes on to the specifics of music. "Accept us as who we are," says Gidi, and like other interviewees, points to how ethnic groupings are seen as the primary building block of social identity and the main actor in social relations. Presenting this point more directly is Gideon, a 26-year-old manufacturer in a pharmaceutical company, when he was asked which kind of differences he identified between Israelis:

Nothing is different. By chance, one was born Moroccan, one Russian, one Ethiopian. What is different, and I told you, is ethnic grouping (He: Ada), there is nothing else different. ... No one gets up in the morning and says, "I have to get myself today an Ethiopian and harass him," or "I hate Russians and I'm going to curse them."

Gideon presents particular ethnic groupings as a random feature of individuals, but more important for the argument in this paper, is that everyone is assigned to one. Thus, ethnic grouping is taken for granted as a basic and unproblematic feature of social difference, as something "one was born" with.

As can be seen from the quotes above, when interviewees make comparisons along ethnic lines, it is especially in relation to Israeli Jews of North African, Middle Eastern, and Russian origins. Observing this pattern gives us a view into the demographic makeup of the places interviewees live, as well as the knowledge of social difference such geographies produce. These demographics consist of the immediate people with whom interviewees interact as coworkers, neighbors, schoolmates and more; thus, the commonsensical act of classifying others to particular ethnicities corresponds to the sounds (e.g., music, languages), smells (e.g., spices, food), variations in color shades, and institutional infrastructure (e.g., synagogue divided by country of origin) that make up the everyday interactional lived experiences of interviewees.

The salient of ethnic labels is not confined to the interactional level of the neighborhood and its demographic makeup, but also at the level of State bureaucracy. State work around ethnic differences is managed in such a way that celebrate those differences as an a-political form of multiculturalism [9-33]. In the context of Ethiopianness, the Sigd is an example of this [14]. A religious holiday unique to Ethiopian Jews, the Sigd got institutionalized at the national level at early $80 \mathrm{~s}$; infused at the city level since 2000; taught in schools; and celebrated annually in Jerusalem in a formal ceremonial script with the president and prime minister.

The intersection of such State work and individual's identification can be seen in the case of Akala, a 26-year-old security guard. As a 20-year-old combat soldier, Akala, along with other soldiers of Ethiopian origin in his unit, were denied participation in the National event of the Sigd in Jerusalem. Frustrated, Akala violated the chain of command and organized the other soldiers to protest, and eventually spent 21 days in detention. While none of the interviewees who used Ethiopian culture as de-stigmatizing resource point to such organized political action, Akala's example points to when such political orientation could be build.

Asking Akala what exactly he thought he was struggling for, what was at stake, and why it was important for him to participate in the ceremony in Jerusalem, knowing he might get detention time, he replied:

Because it's a holiday of the community, and I respect that. It's something, you know, that comes with your family. It's a tradition and you cannot just say I don't feel like it, and I'm not going. It's something that needs to be respected. ... just like you respect ... the rest of the holidays. This is a holiday too.

Akala's reference to family and collective tradition gives us another dimension of how the use of Ethnic Culture is sustained as meaningful over time. Although Akala's use was pragmatically constructed and linked to institutional 
work, it also resonates in important ways with kinship relations, communal activities, collective history, inter-generational continuity, and more. This example points to the ways in which Ethiopianness is experienced by some of the interviewees as a thick cultural experience that is worth protesting [53].

\section{2. "It Is Not the Dress That Makes a Person": Universalism as an Equalizer Resource}

The second strategy highlighted in this paper is "Universalism" as an equalizing resource for de-stigmatization. Universalism as a de-stigmatization strategy, explained by Lamont et al. [4: 396-398], is a claim to universal equality among all individuals and groups, a claim that is carried out by privileging criteria applicable for all human beings. Such an approach can take certain variations, as people can ground their Universalism on a religious basis (we are all children of God), on biology (course of life and death), or on other all-inclusive principals [4]. This strategy stands in tension with the use of Ethnic Culture and was used only by a few of the interviewees. While the use of Ethnic Culture naturalized one type of group differences as commonsensical, the use of Universalism rejects all group differences as non-relevant, to the point of arguing that the act of assigning people to distinctive group categories can itself lead to a discriminatory disposition. However, the common attitude towards group differences was not denial, but dismissal as meaningless and irrelevant for social relations and individual self-worth. This perspective was presented as a moral stand on how social relations should be enacted, and as the way in which interviewees guided their interactional conduct.

\subsubsection{Multiplicity of Labels}

Unlike the use of Ethiopian culture, which interviewees accounted almost exclusively to ethnic labels, interviewees who privileged Universalism's approach accounted for multiple axes of group differences. However, skin color, race, sex, religion, nationality, and other principals of differentiation were talked about only to be dismissed as meaningless. Israela, a 31-year-old housewife, exemplifies this theme:

One is black, one is white, but our course of life - death, birth-it's the same. What is the difference? Our external appearance. For this you say: "don't look at the jar, but at what's inside it." People need to internalize it. It is not the dress that makes a person. It's not externally what makes a person.

In contrast to the use of Ethnic Culture, in which the metaphoric (ethnic) dress does makes a person, a vessel to display a distinctive type of self, here such a dress is understood as hiding a more meaningful and universal type of self. A firm expression of this theme is delivered by Sarit, a 30-year-old, a non-professional clerk in an accounting office. After a series of questions about the ways to deal with stigmatization and discrimination, Sarit seeks to clarify that there are no significant group differences among all individuals:

There is no difference, no difference between anybody. Nothing, nothing. It's a bunch of nonsense. This [group difference] is not what makes you a human being. ... My children will learn that there is no difference. Not between Christians, Muslims and Jews. No, there is no difference there. End of point. I see that they are even Rabbis, Oh God! [who act immoral] ... No, that's not what makes a person. I think that a human being is a human being. He is a human being in his individuality, as himself. Not in his clothing, not in his group affiliation, not in his religion, not anything. All [these differences] are a bunch of bullshit. And it's just nonsense, nonsense, just nonsense. Give me a break. ... There are no differences between race and sex, and color, religion, ethnicity.

Sarit, like other interviewees who use Universalism, but unlike those using Ethiopian culture, has no difficulty recognizing different categorical principles of division - "race and sex, and color, religion, ethnicity." Her rejection of them as meaningless should be understood within the context of her highly individualistic framework for evaluation of individual worth and its effect of detachment from group affiliation and the stigma it might carry.

What is worth noting is that even when interviewees recognize and reject various categorical differences, especially when the conversation is linked to the texture of their lived experiences, here, too, we see a patterned use of ethnic categories. Indeed, when interviewees talked about concrete examples and comparisons to out-group members, the rejection of group differences tended to work through ethnic labels. Shay, 28-year-old and unemployed, mentioned how he got into heated dispute with an Ethiopian-Israeli friend of his. The dispute was over a newspaper article that covered a "heroic act of an army officer," and was particularly over the mentioning of officer's Ethiopian origin. While his friend was "proud" of such mentioning, Shay was thinking:

I look at myself and said, so what if he is Ethiopian? That's what interest you? The fact that he is Ethiopian makes it a grandiose story? If he was an Ashkenazi officer? Or Moroccan? Or Yemenite?

The use of Universalism comes with the individuals' detachment from group identity, and as such, from the various stigmatized notions of Ethiopianness. However, like Shay above, such detachment was not done as Ethiopians who wanted to be recognized outside of the confines of such a particular identity or the associated stigmatized notions, but as moral subjects presenting moral criteria for 
social relations. As moral subjects, it also enables them be critical of their in-group members. Later in the interview, using interviewees' labels of Blacks and Whites, when I asked particularly about the reasons for discrimination against Blacks, Sarit highlights that racism is a universal phenomenon (i.e., exists among all); stating that it exists among blacks, too. Likewise, Mulu, a 28-year-old non-professional clerk in a public health clinic, adds that among Ethiopians, too, racist sentiments exist and that racism is part of the "human character" that can be overcome:

Yes. Because also Ethiopians are racist towards groups among them, it is something that it's grinded in peoples. As long as there isn't a basic familiarity with other people, there will always be this fear of the strange and unknown.

In the following and final section, I discuss how highlighting these variations in de-stigmatized strategies sheds light on the different ways in which the broader social context participates in shaping these two lines of action as relevant and meaningful. Specifically, I discuss how we can rethink the working of national boundaries and racial categories in the context of working class Ethiopian Israelis' stigma management.

\section{Conclusions}

In this paper I explored variations in the de-stigmatization processes within one segment of a particular group [1]. I presented two types of cultural resources deployed by working class Ethiopian Israelis: the use of Ethnic Culture and Universalism. Previous studies on Ethiopian Israelis' de-stigmatization strategies emphasize two poles: emphasizing difference using transnational notions of blackness, on the one hand; and emphasizing resemblance using local national resources of ethno-religious peoplehood, on the other hand. This study further develops our understanding of the range of the culture resources available to Ethiopian Israelis to transform stigmatized relations. And the mediating relations these resources have with everyday lived experience and the national context.

The use of Universalism neither relies, nor is organized in relation to any particular notion of national or transnational peoplehood. This strategy was found among stigmatized individuals in various places and groups around the world [49-4] and might present a very basic frame to constitute horizontal relations with Others. The use of Ethnic Culture does not link to any explicit connection to the national culture either. However, it is mediated by the national context in two important ways. First, its commonsensical character is sustained by national structures - both State institutional work and formal narratives - in which ethnic classification becomes salient in making sense of social difference. Second, positioning one's ethnic category in the categorical set of horizontal relations corresponds to the local national ethos and the symbolic sanctioning of its use in a vertical or politicized form [54].

The use of Ethnic Culture has close relations with forms of everyday interactional order, in which working class Ethiopians and non-Ethiopians present and recognize each other as members of valid and meaningful ethnic groupings. Furthermore, Ethiopianness as an ethnic distinctiveness is linked to a range of cultural practices and communal activities among Ethiopians, which participate in sustaining it as meaningful over time. Accounting for these conditions helps us understand how ethnic identification is sustained as a source of value and de-stigmatization amidst racial boundaries and conflict [4]. It also reminds us that although Jewishness is the prime organizing principle of belonging, and the condition of full access to material and symbolic resources in Israel, it does not cancel the working of other principles of difference, which might go unnoticed as nested [53-55]. Moreover, other principles of difference might be especially powerful under particular configurations of class and geography, and as such, with an important structuring effect on the ways stigma management is carried out.

This paper's empirical approach might help us understand other social actions in which ethnicity plays a role, but goes unnoticed, such as organized Black political identification and mobilization [15-49]. Ethiopian Israelis' political mobilization in recent years is increasingly tied to varied notions of global Black political subjectivity [11]. This change, for example, invites us to specify empirically when and how the political language of race resonates with people's experiences and alters their patterns of identification, interactions, and political mobilization [55]. An empirical approach like this will contribute to our ability to explain the working of categories of difference such as race, ethnicity, and nationality in the context of organized political action and day-to-day life, and do so in a way that is closer to people's layered complexity, and at times contradictory, lived experience.

\section{Acknowledgements}

I wish to thank Hila Sharon and Eszter Bihari for their helpful comments.

\section{REFERENCES}

[1] Lamont, M., Silva, G. M., Guetzkow, J., Welburn, J., Mizrachi, N., Herzog, H., \& Reis, E. Getting Respect: Dealing With Stigma And Discrimination In The United States, Brazil And Israel. Princeton, NJ: Princeton University Press, 2016.

[2] Mizrachi, N. and Herzog, H. "Participatory Destigmatization Strategies among Palestinian Citizens of Israel, Ethiopian Jews and Mizrahi Jews in Israel," Ethnic and Racial Studies, 35(3): 418-435, 2012.

[3] Guetzkow, Joshua and Idit Fast. "How Symbolic Boundaries 
Shape the Experience of Social Exclusion: A Case Comparison of Arab Palestinian Citizens and Ethiopian Jews in Israel," American Behavioral Scientist 59(15): 1-22, 2016.

[4] Brubaker, Rogers. "Ethnicity, Race, and Nationalism," Annual Review of Sociology 35(1): 21-42, 2009.

[5] Lamont, Michele, Ann Morning, and Margarita Mooney. "North African Immigrants Respond to French Racism: Demonstrating Equivalence through Universalism," Ethnic and Racial Studies 25(3): 390-414, 2001.

[6] Lamont, Michèle, Mizrachi, Nissim. "Ordinary People Doing Extraordinary Things: Responses to Stigmatization in Comparative Perspective," in: Lamont, M., Mizrachi, N. (Eds.), Ethnic and Racial Studies, 2012.

[7] Aharon-Gutman, Meirav. "The Iron Cage Of Ethnicity: Ethnic Urban Enclaves And The Challenge Of Urban Design," Urban Design International, 19(2): 144-158, 2014

[8] Motzafi-Haller, Pnina. In the Cement Boxes: Mizrahi Women in the Israeli Periphery. Jerusalem: Magnes Press, 2012. [Hebrew]

[9] Sagiv, Talia. On the Fault Line: Israelis of Mixed Ethnicity. Tel Aviv: Hakibbutz Hameuchad, 2014. [Hebrew]

[10] Shenhav, Yehouda and Y. Yonah (Eds.). Racism in Israel. Jerusalem and Tel Aviv: The Van Leer Jerusalem Institute and Hakibbutz Hameuchad, 2008. [Hebrew].

[11] Ben-Eliezer, Uri. "Becoming a Black Jew: Cultural Racism and Anti-Racism in Contemporary Israel," Social Identities 10(2): 245-266, 2004.

[12] Mizrachi, N. and Zawdu, A. "Between Global Racial and Bounded Identity: Choice of Destigmatization Strategies among Ethiopian Jews in Israel," Ethnic and Racial Studies, 35(3): 436-452, 2012.

[13] Sasson-Levy, Orna, and Avi Shoshana. "'Passing' as (Non) Ethnic: The Israeli Version of Acting White," Sociological Inquiry 83(3): 448-72, 2013.

[14] Abbink, Jan. The Falashas In Ethiopia And Israel: The Problem Of Ethnic Assimilation. Nijmegen, Netherlands: Institute for Cultural and Social Anthropology, 1984.

[15] Kimmerling, Baruch. Immigrants, Settlers, Natives: Israel Between Plurality of Cultures and Cultural Wars. Tel Aviv: Am Oved, 2004. [Hebrew]

[16] Vanda, Hananya. Beta Israel in Tigray - An Ethno-Archaeological Perspective. Unpublished Dissertation Manuscript. Department of Bible, Archaeology and Ancient Near Eastern Studies, Ben- Gurion University, forthcoming. [Hebrew]

[17] Bard, Mitchell G. From Tragedy to Triumph: The Politics Behind the Rescue of Ethiopian Jewry. Westport, CT: Praeger Publishers, 2002.

[18] Zawdu Gebyanesh, Adane. "A View from Below: De-stigmatization Strategies among Ethiopian-Israeli." M.A Thesis, Department of Sociology and Anthropology, Tel Aviv University, Tel Aviv, 2001. [Hebrew]

[19] Shabtay, Malka. Ethiopian Jews Seeds Of Beta Israel: Their Journey From Falashmura To Beta Israel To Ethiopian Jews. Jerusalem: Lsoan Tzhahh, 2006. [Hebrew]
[20] Kaplan, Steven and Hagar Salamon. Ethiopian Immigrants In Israel: Experience And Prospects. London, UK: Institute for Jewish Policy Research, 1998.

[21] Vanda, Hananya. "Amharaization in the Study of Ethiopian Jewry: Tigray's Jews in an Ethno-Archaeological Perspective," presented in: Seeing the World: Categorization and Anthropological Knowledge, Anthropology of Knowledge Conference, The Israeli Anthropological Association, 2008. [Hebrew]

[22] Israel Central Bureau of Statistics. (2015, November 9). The Ethiopian Population in Israel. Retrieved: http://www.cbs.go v.il/reader/newhodaot/hodaa_template.html?hodaa $=2015113$ 02

[23] Hertzog, Esther. Immigrants And Bureaucrats: Ethiopians In An Israeli Absorption Center. New York: Berghahn Books, 1999.

[24] Herzog, Esther. "The Role of Diseases in Constructing Bureaucratic Patronage Over Ethiopian Immigrants in Israel," Anthropology of the Middle East 5(1): 71-92, 2010.

[25] Blevtchin, Yoel. "The Ethiopian Community From Other Perspectives: Findings From The Data," Paper presented at the 11th annual conference, The Israeli Centre for Third Sector Research, Beer Sheva, 2008. [Hebrew]

[26] Taub Center Staff. Education and Employment Among Ethiopian Israelis. The Taub Center for Social Policy Studies in Israel, 2015. [Hebrew]

[27] Swirski, Shlomo, and Barbara Swirski. Ethiopian Jews in Israel: Housing, Employment and Education. Tel Aviv: The Adva Center, 2002. [Hebrew]

[28] Mengistu, Germaw and Eli Avraham. "Others Among Their Own People": The Social Construction of Ethiopian Immigrants in the Israeli National Press Authors," Communication, Culture \& Critique, 8: 557-575, 2015.

[29] Bahahr, Almog. The Ethiopian community in the media (Special Report). Jerusalem: Israeli Association for Ethiopian Jews, 2004. [Hebrew]

[30] Degani, Avi and Rina Degani. The Influence Of The Media On The Perceptions Towards The Ethiopians (Special Report). Jerusalem: Israeli Association for Ethiopian Jews, 2004. [Hebrew]

[31] Seeman, Don. One People, One Blood: Ethiopian-Israelis And The Return To Judaism, New Brunswick, N.J.: Rutgers University Press, 2009.

[32] Gonchel Yaacov. "Look Not Upon Me, That I Am Swarthy," Eretz Acheret, 30: 20-24, 2005. [Hebrew]

[33] Shenhav, Yehouda. The Arab Jews: A Postcolonial Reading Of Nationalism, Religion, And Ethnicity. Stanford, Calif.: Stanford University Press, 2006.

[34] Dahan Kalev, Henriette and Maya Maor. "Skin Color Stratification in Israel Revisited," Journal of Levantine Studies, 5(1): 9-33, 2015.

[35] Ojanuga, Durrenda. "The Ethiopian Jewish Experience as Blacks in Israel," Journal of Black Studies 24: 147-158, 1993.

[36] Ben-David, Amith, and Avital Tirosh Ben Ari. "The Experience of Being Different: Black Jews in Israel," Journal of Black Studies 27(4): 510-527, 1997. 
[37] Walsh, Sophie D. and Rivka Tuval-Mashiach. "Ethiopian Emerging Adult Immigrants in Israel Coping with Discrimination and Racism," Youth \& Society 44(1): 49-75, 2012.

[38] Shabtay, Malka. "Living With Threatened Identity: The Differences Skin Color Life Experiences Among Young And Adolescent Ethiopian Immigrants In Israel," Megamot 1(2): 97-112, 2001A. [Hebrew]

[39] Shabtay, Malka. Between Reggae And Rap: The Challenge Of Belonging Of Ethiopian Youth In Israel. Tel-Aviv: Tcherikover, 2001B. [Hebrew]

[40] Anteby-Yemini, Lisa. "Marginal visibility: Ethiopian immigrants in Israel", In E. Lomsky- Feder \& T. Rapoport (Eds.), Visibility in Immigration: Body, Gaze, Representation, Jerusalem and Tel Aviv: The Van Leer Jerusalem Institute and Hakibbutz Hameuchad, 2010. [Hebrew].

[41] Goffman, Erving. Stigma. New York: Simon \& Schuster, 1986.

[42] Pescosolido, Bernice A. and Jack K. Martin. "The Stigma Complex," Annual Review of Sociology 41(1): 87-116, 2015.

[43] Lamont, Michèle. "Responses to Racism, Health, and Social Inclusion as a Dimension of Successful Societies," in: Hall, Peter A., Lamont, Michèle (Eds.), Successful Societies: How Institutions and Culture Affect Health. London: Cambridge University Press, 151-169, 2009.

[44] Yadgar, Yaacov. "A Post-Secular Look at Tradition: Toward a Definition of 'Traditionism." Telos 156: 77-98, 2011.

[45] Quirin, James Arthur. The Evolution Of The Ethiopian Jews: A History Of The Beta Israel (Falasha) To 1920. Philadelphia: University of Pennsylvania Press, 1992.

[46] Clarke, Adele E. Situational Analysis: Grounded Theory After the Postmodern Turn. Thousand Oaks: Sage Publications,
2008.

[47] Gubrium, Jaber F., and James A. Holstein. Handbook Of Interview Research: Context \& Method. Thousand Oaks, Calif: Sage Publications, 2002.

[48] Rubin, Herbert J. and Irene Rubin. Qualitative Interviewing: The Art Of Hearing Data. Thousand Oaks, Calif.: Sage Publications, 2005.

[49] Wimmer, Andreas. "The Making And Unmaking Of Ethnic Boundaries. A Multi-Level Process Theory," American Journal of Sociology 113(4): 970-1022, 2008.

[50] Barth, Fredrik. Ethnic Groups and Boundaries: The Social Organization of Culture Difference. Bergen; London: Universitetsforlaget and Allen \& Unwin, 1969.

[51] Hattam, Victoria. In the Shadow of Race: Jews, Latinos, and Immigrant Politics in the United States. Chicago: University of Chicago Press, 2007

[52] Ynet, (2016, August 31). "The Problem Started Long Before The Appointment Of Alshich: More Charges To Ethiopians, More Minors In Prison.” Retrieved: http://www.ynet.co.il/art icles/0,7340,L-4848465,00.html [Hebrew]

[53] Wimmer, Andreas. Ethnic Boundary Making: Institutions, Power, Networks. New York: Oxford University Press, 2013.

[54] Herzog, Hanna. "Midway between Political and Cultural Ethnicity: An Analysis of the Ethnic Lists in the 1984 Elections." Pp. 87-118 in Israel's Odd Couple: The 1984 Elections and National Unity Government, edited by E. Daneil, H. Penniman, and S. Shmuel. Detroit, MI: Wayne State University Press, 1990.

[55] Brubaker, Rogers, Margit Feischmidt, Jon Fox, and Liana Grancea. Nationalist Politics and Everyday Ethnicity in a Transylvanian Town. Princeton, NJ: Princeton University Press, 2006. 